\title{
Santos e sacramentos no cotidiano dos trabalhadores de Macapá (1948-1964)
}

\author{
Sidney da Silva Lobato ${ }^{[1]}$
}

\begin{abstract}
Resumo
Entre 1948 e 1964, a Igreja Católica ampliou rapidamente sua envergadura institucional no Território Federal do Amapá. Neste território, ocorreu a chegada de missionários italianos e a consequente formação de diversas paróquias. Os párocos procuraram então depurar as práticas religiosas dos leigos, seguindo os rígidos princípios da ortodoxia eclesiástica. Neste artigo, procuramos enfocar o esforço destes leigos para defender uma religiosidade na qual o culto aos santos ocupava um lugar central, em detrimento da importância que os padres atribuíam aos sacramentos. Procuramos também demonstrar que, diante deste esforço, muitas vezes os clérigos recuaram.
\end{abstract}

Palavras-chaves: catolicismo popular; romanização; Amazônia

\section{Santos y sacramentos en la vida cotidiana de los trabajadores de Macapá} (1948-1964)

\section{Resumen}

Entre 1948 y 1964, la Iglesia Católica se expandió rápidamente en su ámbito institucional, en el Territorio Federal de Amapá. En este territorio, ocurrió la llegada de los misioneros italianos y la consiguiente formación de diversas parroquias. Luego los sacerdotes trataron de purificar las prácticas religiosas de laicos, siguiendo los estrictos principios de la ortodoxia eclesiástica. Tratamos de enfocar los esfuerzos de estos laicos para defender una religión en la que el culto a los santos tomara un lugar central en detrimento de la importancia que asignara a los sacerdotes los sacramentos. También tratamos de demostrar que a la vista de este esfuerzo, a menudo clérigos se retiraron.

Palabras-claves: catolicismo popular; romanización; Amazonia.

\section{Saints and sacraments in everyday life of the Macapás workers (1948-1964)}

\begin{abstract}
Between 1948 and 1964, on Amapá Federal Territory, the Catholic Church quickly amplified its institutional size, creating a lot of parochial communities, with fixed italian missionaries. Orthodoxly, they attempted cleaning laymen's religious practices. In this article, we focus laymen's struggle to defend their saints, even though priests had considered saints less important than sacraments. We also demonstrate that many times italian missionaries retreated in face of this struggle.
\end{abstract}

Keywords: popular catholicism; romanization; Amazon.

\section{Saints et sacraments au quotidien des travailleurs de Macapá (1948-1964)}

\section{Résumé}

De 1948 à 1964, l'Eglise Catholique a développé rapidement son influence institutionnelle dans le Territoire Fédéral de l'Amapá. Dans ce contexte, les missionnaires italiens sont arrivés et, à partir d'ici, les paroisses ont été institué. Par conséquence, les curés ont essayé de discipliner les pratiques religieuses des fidèles laïcs, en faisant respecter les principes de l'orthodoxie ecclésiastique. Dans cet article, nous voulons attirer l'attention sur les efforts des membres laïcs qui ont défendu leur religiosité, où le culte aux saints avait le rôle principal, au détriment de l'importance que le clergé accordait aux sacrements. Par ailleurs, nous voulons montrer qu' en face de cette résistance, plusieurs fois les clercs ont freiné son élan d'imposer leur approche pastorale.

Mots-clés: catholicisme populaire; romanisation; Amazonie 

objetivo deste artigo é analisar o conflito entre a ortodoxia clerical e o festivo catolicismo popular existente em Macapá, entre 1948 e 1964. Para melhor entender este conflito, é necessário partir do acontecimento que alterou o velho equilíbrio da vida religiosa na região da foz do Amazonas: a chegada à capital do Amapá dos padres do Pontifício Instituto das Missões Estrangeiras (PIME), em 1948. O PIME classificava a Amazônia como área de cristianização imatura e, portanto, carente da sua ação missionária. ${ }^{2}$ Numa entrevista publicada na revista Le Missioni Cattoliche, em dezembro de 1962, o bispo da Prelazia de Parintins, Arcangelo Cerqua, declarou que apesar da região amazônica não ser uma das clássicas "zonas de paganismo" (como as encontradas na África, na Ásia e na Oceania), ela podia ser plenamente considerada uma área "de missão", pois "a Igreja não foi ali fundamentada de modo estável, dependendo quase exclusivamente de contribuições de pessoal e meios provenientes do exterior". Tal situação decorria, em grande parte, de uma atuação clerical que ao longo dos séculos foi descontínua e, em algumas paragens, esporádica.

No século XVII, as populações indígenas que habitavam o atual espaço amapaense recebiam apenas visitas eventuais de missionários franciscanos, jesuítas e capuchinhos, os quais promoviam descimentos (arregimentação de indígenas) para as proximidades de Belém do Grão-Pará. A fundação da paróquia de Macapá, em 1752, não foi seguida por um genuíno "esforço catequizador" ou por uma presença constante de padres. O mesmo pode ser dito das paróquias posteriormente criadas na margem esquerda do rio Amazonas: ade Mazagão (em 1845) e da cidade de Amapá (em 1904).

A fundação da paróquia de Santarém (cidade situada no oeste do Pará), no ano de 1903, e a subordinação de Macapá àquela circunscrição, marcou o início de uma presença mais estável de sacerdotes na região da foz do Amazonas. Foi neste período que, atendendo a um pedido do bispo da prelazia santarena, Armando Bahlmann, os missionários alemães da Congregação da Sagrada Família se estabeleceram na ilha de Santana (distante cerca de 15 quilômetros da capital amapaense), de onde partiam para visitas pastorais e onde permaneceram até maio de 1948. A congregação, contudo, tinha seus limites. Nas palavras do padre Angelo Negri:

\footnotetext{
${ }^{2} \mathrm{~A}$ vinda dos missionários do PIME para o Brasil tem também relação direta com várias transformações que o Pontifício Instituto sofreu no pós-guerra. Novos seminários e sedes então criados na Itália passaram a exigir que aí ficasse um número cada vez maior de padres. Alguns dos missionários recém-ordenados passaram então a protestar, pois queriam partir para áreas de missão. O fechamento da China para os sacerdotes católicos, ocorrido após a Guerra, comprometeu a sustentabilidade da "vocação asiática" do PIME. Neste quadro, a solução foi a rápida abertura de novas frentes em áreas antes não consideradas ad gentes (carentes da ação missionária). Sobre estas questões ver: Gheddo (2000, p. 186-188).

${ }^{3}$ La Chiesa missionaria nell'Amazzonia brasiliana, Le missioni cattoliche, n. 3453, dez. 1962, p. 484. No original: "(...) che, pur essendo abitati in prevalenza da popolazioni cattoliche, possono a pieno diritto essere considerati 'di missione', in quanto la Chiesa non vi è ancora stabilmente fondata e deve dipendere quasi esclusivamente da aiuti di personale e di mezzi provenienti dall'estero".
} 
os missionários alemães que estavam antes de nós haviam trabalhado bem, eram verdadeiramente heroicos e bem organizados. No Território do Amapá havia capelas, registros de batismos, encarregados das orações, grupos de senhoras do Apostolado da Oração e de homens da Congregação Mariana. Porém, os missionários eram dois ou três, no máximo quatro, e fora de Macapá eram vistos apenas uma vez ou duas por ano. ${ }^{4}$

Esta descontínua e numericamente pouco expressiva presença de padres junto aos leigos foi um dos fatores que concorreram para o aparecimento de um pujante e heterogêneo conjunto de vivências da fé. Para os escrupulosos clérigos,tais vivências geralmente estavam distantes do que fora idealizado pela doutrina da Igreja. Mas, isso não impedia que os leigos percebessem suas práticas como algo genuinamente católico. ${ }^{5}$ Este catolicismo popular tinha as seguintes características gerais: a) o protagonismo dos leigos; b) a centralidade dos sacramentais; c) a relação familiar com o sagrado; d) a tolerância religiosa (abertura ao pluralismo religioso); e) e o gosto pela expressão festiva e teatralizada da espiritualidade. Conforme demonstraremos abaixo, todas estas características foram reprovadas e atacadas pelos missionários do PIME, no período que vai de 1948 até 1964. Também como indicaremos adiante, após o Concílio Vaticano II, grande parte do clero latino-americano passou a ver com mais simpatia o catolicismo popular. Abrir-se-á, então, o caminho para o desenvolvimento de uma catequese pautada na "inculturação".

\section{Festas de santos}

Seguindo uma tradição ibérica, ao longo de décadas e décadas os trabalhadores da Amazônia formaram irmandades leigas, em torno das quais orbitava a vida religiosa. A principal função destas pequenas associações era a realização de festejos para homenagear os seus respectivos santos. Durante as observações que fizera em Gurupá, no final da década de 1940, o antropólogo Eduardo Galvão anotou acerca das irmandades: "os leigos que as dirigem não têm qualquer relação com os padres, preferindo evitá-la”. Esta preferência era motivada pela reprovação severa dos sacerdotes às práticas adotadas no culto aos santos, que incluíam: folias, rezas, bailes e comedorias. Entre os irmãos, havia uma

\footnotetext{
${ }^{4}$ No original lê-se: "i missionari tedeschi che erano prima di noi avevano lavorato bene, erano stati veramente eroici e bem organizzati. Nel Territorio dell'Amapá c'erano capelle, registri dei battesimi, incaricati della preghiera, gruppi di signore dell'Apostolato della Preghiera e di uomini della Congregazione Mariana. Però i missionari erano due o tre, al massimo quatro, fuori di Macapá la gente li vedeva uma volta o due l'anno". Os primeiros missionários do PIME a virem para o Amapá encontraram neste território dois padres da Sagrada Família numa situação desoladora: debilitados fisicamente e isolados, devido à infundada e popularizada desconfiança de que eles tinham praticado espionagem em favor das forças alemãs, durante a Segunda Guerra Mundial. (Gheddo, 1998, p. 34-36, 48)

${ }^{5}$ Em entrevista publicada na revista Tempo, o historiador João José Reis afirmou: "toda religião tem centro e periferia. No centro estão seus líderes 'burocráticos', para usar o conceito de Weber, e a doutrina, a ortodoxia; na periferia estão os fiéis, um grande número dos quais se localizam também nas fronteiras da heterodoxia, contrabandeando elementos de outros registros religiosos, enfim os que 'pecam' a roldão". O catolicismo popular forma-se nesta zona periférica da Igreja católica, onde pode se fortalecer amplamente quando o centro é fraco, como ocorreu no caso que estamos estudando. Ver: Reis (2001, p. 255).
} 
definição de papéis específicos, como: procurador (responsável pela manutenção do patrimônio da irmandade, incluindo a imagem do santo); tesoureiro (aquele que deveria cuidar do controle de receitas e despesas); secretário (era dele a função de fazer registros das atividades em livro próprio); zeladeira (a ornamentadora do altar do santo); andador ou mantenedor (o comandante da folia, durante a qual se coletavam os donativos); e o mestre sala (o disciplinador das festas e solista de cânticos durante a folia). Anualmente, também eram eleitos juízes e mordomos. Ao juiz da festividade cabia arcar com os maiores gastos do auge dos festejos: o "dia do santo". O mordomo assumia o encargo de custear a realização das ladainhas (depois dela eram oferecidos: café, pães ou beijus) (Galvão, 1955, p. 48-62).

\section{Após o Concílio Vaticano II, grande parte do clero latino-americano passou a ver com mais simpatia o catolicismo popular}

No pós-guerra, a mais conhecida irmandade leiga de Macapá era a que realizava a festa do Marabaixo. ${ }^{6}$ Relembrando o modo como era organizado o Marabaixo em meado do século XX, a festeira Benedita Ramos relatou-nos em entrevista: "naquele tempo, cada um pagava a sua sociedade do Espírito Santo e da Trindade e, quando chegava a época da festa, saíam três festeiros e o novenário, que mandava dizer a novena e a missa dos santos". ${ }^{7}$ No Domingo do Mastro (início do ciclo festivo), os homens arrancavam o tronco escolhido para suportar a bandeira do "santo" e jogavam capoeira diante da Igreja de São José. Na Quarta-feira da Murta, as mulheres entoavam as canções novas (os ladrões), também na frente daquela igreja. A partir de 1948, a entrada das coroas (representações da Santíssima Trindade e do Divino Espírito Santo) na matriz tornou-se o principal ponto de tensão entre os agentes do Marabaixo e o clero.

O etnógrafo Nunes Pereira fez observações acerca do Marabaixo macapaense, em agosto de 1949,ou seja, pouco mais de um ano depois da chegada

\footnotetext{
${ }^{6}$ Trata-se de uma festa tradicional, que remonta ao Período Colonial. Famílias açorianas foram enviadas, em 1751, por Francisco Xavier de Mendonça Furtado para povoar a região da foz do rio Amazonas. Estas famílias trouxeram consigo a tradição portuguesa da festa do Divino Espírito Santo. Esta festa incorporou rituais da cultura popular dos negros do extremo-norte do Brasil - como a quebra da murta (arbusto utilizado para espantar maus espíritos), as cantigas ao som do batuque de tambores (caixas de Marabaixo, feitas de couro e madeira) e a gengibirra (bebida feita a base de gengibre e cachaça). A festa do Marabaixo segue o calendário litúrgico: inicia no domingo do Pentecostes e se encerra como a homenagem à Santíssima Trindade. Ver: Motinha (2003, p. 275-328); e Oliveira, (1999, p. 02-08).

Benedita Guilherma Ramos nasceu em 1925. Ela foi entrevistada no dia 06 de maio de 2008. Atualmente, em Macapá, ela é reconhecida como uma das mais importantes lideranças da festa do Marabaixo do bairro do Laguinho.
} 
dos primeiros missionários do PIME. ${ }^{8}$ Segundo Nunes Pereira, o acirrado conflito entre os padres do PIME e os leigos que promoviam o Marabaixo só não foi pior devido à intercessão do governador do Território Federal do Amapá, Janary Nunes, em favor dos marabaixeiros. Pereira afirmou também: que a gente do Marabaixo não mais entrava na igreja matriz para aí realizar "uma série de cerimônias", que as suas danças e as suas lutas eram "olhadas com menospreso [sic.] pelos padres" e que, por isso mesmo, o povo as defendia "com sobranceira veneração" (Pereira, 1951, p. 99-100).

A força com que os devotos defendiam suas festas de santo das investidas clericais já aparecia numa carta escrita na década de 1920 pelo padre Júlio Maria Lombaerde, missionário da congregação da Sagrada Família. Ele afirmava que para os "ignorantes" as festas religiosas "constituem toda a sua religião" e que "atacar esses abusos grosseiros, seria enfurecê-los e afastá-los". Por fim exortava: "é preciso, portanto, pouco a pouco, substituir essas festas grotescas por festas religiosas e fazer com que este povo compreenda que sua religião é incompleta" (Lombaerde, 1991, p. 281).Padre Júlio Maria conhecia muito bem o apego dos populares a seus santos. Em entrevista dada a Ivan Fornazier Cavaliere, em julho de 1980, o subtenente do Exército Zacarias Teixeira Leite (então com 77 anos) afirmou que Lombaerde combatia o Marabaixo porque o via como batuque e bebedeira associada à exploração de dinheiro. Por isso, este padre fechava a igreja, "mas o povo fincava mastros na frente da matriz". O militar afirmou ainda que era algo tradicional a coroa de prata do Divino Espírito Santo pernoitar na Igreja de São José, para depois ser recolhida pelo festeiro "entre orgias populares".Condenando isto, o missionário da Sagrada Família "quebrou a coroa de prata do Divino e mandou entregar os pedaços ao festeiro do Marabaixo". O povo quis invadir a casa do clérigo, no que foi impedido pelo Coronel Teodoro Mendes, então intendente de Macapá (Cavaliere, 1981, p. 15).

A quebra da coroa do Divino pelo padre Maria Lombaerde tornou manifesta as contradições fundamentais entre o catolicismo popular e o catolicismo oficial em Macapá. Para o clérigo, a coroa era uma representação de pouca importância do ente sagrado cultuado. Mas, para os devotos, ela era a própria materialização (presença efetiva) do Espírito Santo. Os padres do PIME, logo que chegaram, perceberam esta diferença e passaram a associar os cultos populares ao fetichismo e à magia. Eles entendiam que, no catolicismo popular, ocorria uma inversão que deveria ser urgentemente corrigida: os fieis valorizavam mais os sacramentais (imagens, velas, fitas, água benta, etc.) do que os sacramentos (batismo, comunhão, crisma, matrimônio, ordem, confissão

${ }^{8}$ Chegaram: dois padres em maio de 1948 (os futuros bispos Aristides Piróvano e Arcângelo Cérqua); sete em junho deste mesmo ano (os padres Vitório Galliani, Angelo Bubani, Carlos Bassanini, Luis Vigano, Mário Limonta, Lino Simonelli, Jorge Basile e mais o irmão Francisco Mazzoleni); e quatro em meado de dezembro ainda de 1948 (Angelo Negri, Simão Corridori, Pedro Locati e Antonio Cocco). Ver: Bubani (1983, p. 15). 
e unção dos enfermos). A doutrina oficial da Igreja afirmava que os fieis deveriam entrar em contato com Deus prioritariamente através dos sacramentos o que era também um modo de afirmação da importância daqueles que iriam (quase que exclusivamente) ministra-los: os padres.

\section{Sacramentos e sacramentais}

Os missionários do PIME fundamentavam suas afirmações de que o trabalho do Instituto estava sendo bem sucedido através da apresentação do aumento substantivo do número de sacramentos ministrados. Após uma desobriga (incursão para atividade missionária) no interior do Amapá, ocorrida em 1954, o padre Angelo Bubani escreveu: "visitei 18 comunidades existentes entre o [rio] Araguari e o Flechal, com 15 escolas. Frutos espirituais: 269 batismos, 191 crismas, 504 comunhões, 489 primeiras comunhões, 59 casamentos". ${ }^{9}$ Numa entrevista realizada em 1964, o padre Piero Gheddo pediu ao então bispo Aristides Piróvano que apresentasse números que refletissem a renovação da vida cristã no Amapá. D. Aristides afirmou que, no início do trabalho do PIME, frequentavam as missas dominicais "poucas dezenas de velhinhas e algumas crianças". Em seguida, ele ressaltou que este quadro havia sido alterado: "agora, entre todas as paróquias da capital, que conta com cerca de 30.000 católicos, temos 6.000 presentes na missa dominical, isto é, cerca de $30 \%$ de todos aqueles que têm o dever de participar". O bispo destacou que, de 1949 a 1963, as comunhões haviam saltado de 21.500 para $280.000 .^{10}$

Em 1979, o segundo bispo de Macapá, D. Giuseppe Maritano, fazendo uma avaliação do trabalho dos missionários no período que vai de 1948 até 1968, afirmou que "se buscava 'sacramentalizar' os fiéis o mais possível". ${ }^{11}$ Se do ponto de vista quantitativo o processo de sacramentalização da vida religiosa macapaense parece ter sido muito bem sucedido, o mesmo não pode ser dito de um ponto de vista qualitativo. Isto porque comumente os significados dos sacramentos não eram os mesmos para padres e fiéis. Foi D. Maritano quem ressaltou: "nota-se entre os nossos católicos o apego radical ao batismo, considerado muitas vezes como um rito mágico para proteger-se contra o espírito do mal e também como garantia de saúde contra a mortalidade infantil"12. O batismo era inserido dentro de uma compreensão de que o bem estar de cada pessoa dependia de um equilíbrio de forças naturais e espirituais (reinos totalmente misturados na religiosidade do povo). Também de acordo com as observações do segundo bispo de Macapá, para muitos católicos, o casamento tinha um sentido que destoava da visão clerical: "a concepção do matrimônio como sacramento e como vida a dois, indissolúvel, ainda tem que ser construída, a parte louváveis exceções. As separações são inúmeras, as uniões ilegítimas

9No original: "ho visitato 18 comunità comprese fra l'Araguarí e il Flechal, com 15 scuole. Fruti spirituali: 269 battesimi, 191 cresime, 504 comunioni, 489 prime comunioni, 59 matrimoni”.(Gheddo, 1998, p. 94-95)

${ }^{10}$ Amapà: missione nell'Amazzonia brasiliana, Le missioni cattoliche, n. 3468, mai. 1964, p. 267.

"Un vescovo in Amazzonia, Mondo e missione, n. 20, out. 1979, p. 532.

${ }^{12}$ Un vescovo in Amazzonia, Mondo e missione, n. 20, out. 1979, p. 530-31. 
também, poderíamos dizer que falta justamente o conceito do matrimônio". ${ }^{3}$ Ocorria, portanto, uma ressignificação dos sacramentos no bojo da experiência dos leigos, cujo conjunto de referências religiosas e morais era muito mais híbrido do que o dos padres.

Se dentro do catolicismo popular os sacramentais ocupavam um lugar mais importante do que os sacramentos, dentre os sacramentais conhecidos havia um que ganhava grande reverência: as imagens de santos. A principal expressão da vida religiosa era a devoção aos santos. Em todas as casas de famílias tradicionalmente católicas havia um pequeno altar ou santuário de madeira lotado de estatuetas enfeitadas com fitas de várias cores e dimensões (cada uma representava uma promessa atendida ou uma graça recebida). Quando chegaram a Macapá, os primeiros padres do PIME encontraram na igreja matriz (a única então existente) uma grande quantidade de imagens de santos. A situação foi assim descrita por D. Aristides Piróvano: "altares sobrecarregados de estátuas e estatuetas (contamos uma dúzia de São Roque e dezenas de outros santos dificilmente identificáveis, estátuas quase todas quebradas ou incompletas), quadros que nenhuma comissão de arte sacra teria aprovado". E mais: "velas e flores de papel, coroas de todo o tipo e até raízes de árvore com vaga forma humana (que encarnavam um santo, claro!)". Além disto, havia fitas de todas as cores. Tantas, afirma Piróvano, que sobre a mesa do altar não havia espaço para a celebração da missa. ${ }^{14}$

\section{Para os "ignorantes" as festas religiosas "constituem toda a sua religião" e "atacar esses abusos grosseiros, seria enfurecê-los e afastá-los"}

Algumas imagens eram consideradas particularmente poderosas e eram, por isso, objeto de grande movimento devocional. Em entrevista feita pelo padre Piero Gheddo, o missionário do PIME Lino Simonelli contou que, no início das missões no Amapá, conheceu uma mulher que viera de Belém com um cogumelo grande e longo - daqueles fibrosos e duros que, na Amazônia, crescem ligados às plantas. $\mathrm{O}$ cogumelo parecia um homem em miniatura. A referida mulher pintou então dois olhos brancos nele e começou a dizer: "este

\footnotetext{
${ }^{13}$ Un vescovo in Amazzonia, Mondo e missione, n. 20, out. 1979, p. 532. No original: "si nota fra i nostri cattolici il radicale attaccamento al battesimo, considerato molte volte come un rito magico per proteggersi dallo spirito del male ed anche come garanzia di salute contro la mortalità infantile". E adiante: "la concezione del matrimonio come sacramento e come vita a due indissolubile è ancora di là da venire, a parte lodevoli eccezione. Le separazione sono numerosissime, le unioni illegittime altrettanto, a volte si direbbe che manca próprio il concetto del matrimonio"

${ }^{14}$ Amapà: missione nell'Amazzonia brasiliana, Le missioni cattoliche, n. 3468, mai. 1964, p. 259. No original: "altari sovraccarichi di statue e statuette (contammo una dozzina si S. Rocco e decine d'altri santi difficilmente individuabili, statue quasi tutte rotte od ammaccate), quadri che nessuna commissione di arte sacra avrebbe approvato, candele e fiori di carta, corone d'ogni genere e persino radici d’albero dala vaga forma umana (che incarnavano un santo, si capisce!) e poi nastri d'ogni colore, tanti nastri che non potevamo assolutamente accetare, anche perchè sulla mensa degli altari non c'era quasi posto per la celebrazione della S. Messa!"
} 
é São Benedito do urupê que veio nos encontrar". Muitas pessoas iam procurar a dona do santo, que fazia procissões, preces públicas, pedia ofertas e distribuía remédios feitos por ela e benzidos pelo santo (Gheddo, 1998, p. 94). ${ }^{15}$ Os donos de santos alcançavam grande prestígio nos lugares onde viviam se as imagens que possuíam fossem consideradas milagrosas. Ou seja, para os devotos, diferentes imagens de um mesmo santo não eram equivalentes em importância. Já para o clero, a equivalência entre elas era absoluta (Maués, 2001, p. 257, 266).

Muitos acreditavam que certas imagens adquiriam as capacidades humanas necessárias para se movimentar e misturar entre as pessoas comuns. No início do século XX, ainda era forte a tradição oral segundo a qual, na Macapá oitocentista, ao caminhar numa certa noite pela praça da matriz,um escravo teria passado perto de um homem muito misterioso. Cismado, o escravo teria dito aos seus senhores que o desconhecido era São José e, ato contínuo, teria morrido. Esta morte súbita fora considerada um sinal de que o relato era mesmo digno de fé (Nunes, 1963b, p. 2). Segundo outra crença popular, o padroeiro da cidade teria participado de alguns dos momentos mais dramáticos da vida dos macapaenses. Durante a Cabanagem (1835-1840), Macapá ficara sem guarnições devido às várias agitações que então ocorriam no Brasil. O São José existente na Fortaleza (estátua de regular tamanho) teria defendido a cidade da invasão das forças cabanas, por meio de rondas noturnas, nas ruas e nas praças. Por isso, no alvorecer, os pés e a túnica da imagem do padroeiro eram encontrados cheios de carrapichos e capins — sinais de suas andanças. Segundo esta tradição oral, o santo também indicava em qual direção estavam os cabanos, pois ficava sempre de frente para onde eles estivessem: Pedreira, Campos, Vila Nova ou ilhas (Nunes, 1963a, p. 2).

Desde o início da colonização, os santos ocuparam um lugar central na vida religiosa das populações da América Portuguesa. Eles, com frequência, tinham mais destaque do que Deus. Jesus Cristo (na forma de menino ou adulta) e o Espírito Santo eram, amiúde, percebidos como santos comuns. Na vida cotidiana dos trabalhadores, os santos eram chamados para ajudar no enfrentamento da insegurança estrutural, para afastar a enfermidade e a morte (Souza, 2000, p. 179). Em março de 1960, um articulista do jornal Amapá escrevia: "à proporção que passam os tempos, mais se evidencia o prestígio da Igreja entre nós, sobretudo em dias dedicados aos santos que nos ajudam a vencer os tropeços naturais da vida diária". ${ }^{16}$ Os santos eram procurados menos como exemplos de virtude e de conduta moral e mais como amigos poderosos e solícitos - prontos a interferir na vida dos homens, para aliviar seus pesos e dores. Em geral, o auxílio deles era invocado através de promessas.

${ }^{15}$ No jornal A voz católica de 04 de fevereiro de 1962, lemos o seguinte: "há alguns anos atrás, determinada senhora residente nesta cidade, resolveu homenagear um São Benedito de Urupé, esculpido em madeira, existente em sua casa". E em seguida: "muito devota logo conseguiu enorme número de adeptos e lá se foi a procissão pelas ruas da cidade” (O Amapá anedótico [seção]. A voz católica (Macapá), n. 119, 4 fev. 1962, p. 5). ${ }^{16}$ Hoje a tarde a procissão de São José..., Amapá (Macapá). n. 1062, 19 mar. 1960, p. 6. 
O devoto poderia oferecer em troca da dádiva: esmerado trabalho na organização de uma festa religiosa, rezas, penitências e outros. A promessa tinha o caráter de uma obrigação mútua, pois caso o santo não cumprisse sua parte poderia "ser posto de castigo" - a imagem poderia, por exemplo, ser virada de frente para a parede, ou colocada dentro de um balde. Caso o pedinte não cumprisse sua parte no contrato, poderia atrair a ira do santo e, com ela, vários malefícios (doenças, insucesso nos negócios, desgostos na vida afetiva, etc.) (Arenz, 2003, p. 147). ${ }^{17} \mathrm{O}$ relacionamento entre fiel e santo ocorria dentro de uma atmosfera de proximidade e emotividade. O que destoava da relação mais distante e formal que o clero estabelecia com o sagrado. Um fato narrado pelo padre Angelo Biraghi (do PIME) demonstra bem esta diferença. Ele fazia uma desobriga na região do vale do rio Piririm (situado no norte do Amapá), quando se deparou com uma situação bastante inusitada:

(...) um dia, chegando a um vilarejo, após a recepção solene conforme o programa, fui visitar imediatamente a capela, ajoelhei-me e comecei a rezar. Após um tempo, curioso, fixei o olhar sobre o altar buscando adivinhar os nomes daquele esquadrão de Santos e Santas, ornamentados com fitas longas e coloridas, colocados sobre os tradicionais três degraus, quase sem deixar espaço para a celebração da Santa Missa.

Num certo ponto, entre aquela multidão de Santos e Santas (eram 26...!) vi algo que de santo não tinha nada e que nunca poderia ser santificado!...

Chamei o primeiro zelador da capela e perguntei:

- Por que este gato de gesso está aqui no altar em meio aos Santos, quase num lugar privilegiado?

Respondeu-me: "sabe, padre, o gato é tão amigo do homem quanto o Santo, é fiel e familiar, está sempre próximo de nós. Além disso, eu não tinha nada mais bonito em casa para enfeitar o altar".

Meus longínquos amigos italianos, o que pensam disso? Eu não me espantei demais. Se essa pobre gente que vê o padre uma vez por ano põe, inocentemente, um gato no mesmo degrau que o Santo - pensei - sei muito bem que na moderníssima e progressista Itália existem outros que às vezes exageram, porque conscientemente veneram mais os gatos que os Santos... Pelo menos estes meus amigos aqui os colocam no mesmo plano!

\footnotetext{
${ }^{17}$ No jornal A voz católica de 09 de fevereiro de 1964, lemos o seguinte comentário: "gente pobre tem uma ideia muito alta da honestidade. Se às vêzes atrasa dois ou três meses no pagamento de sua cota, pede desculpa ao Padre. E, custe o que custar, essa gente nunca passa santo para tráz. Paga até o último tostão o que prometeu dar". Ainda existe o milagre: história de uma construção. A voz católica (Macapá), n. 224, 9 fev. 1964, p. 3.
} 
Para concluir, devo dizer, contudo, que naquele dia mesmo mandei o gato de gesso enriquecer a pesca beneficente que era realizada em favor da capela. ${ }^{18}$

Primeiramente, é preciso destacar que a citação demonstra a percepção que se tinha do santo: alguém que é amigo e familiar. Alguém que se pode tratar como se fosse um parente, por meio de uma abordagem franca e emotiva. Os santos eram aliados importantes na luta cotidiana pela sobrevivência. Luta que não se travava meramente num plano material, pois a realidade não poderia então ser esvaziada de seu sentido espiritual. Membro da unidade doméstica, o santo podia mobilizar agentes e forças que estavam fora do alcance dos devotos. Sua mediação era invocada a partir do reconhecimento de que nem tudo dependia dos homens e era nas situações em que as limitações humanas ficavam claramente expostas que ele mais era chamado a agir: doenças, viagens em pequenas embarcações pelos grandes rios, ataque de pragas (a plantações e a rebanhos), desemprego e outros. Dentro da unidade familiar, o santo não convivia apenas com mulheres e homens. Os animais domésticos também eram membros importantes e queridos da família, como evidenciou o zelador da capela do Piririm. Bichos como cães, gatos e papagaios tinham nomes e eram contabilizados como fiéis companheiros dos momentos de alegria e de tristeza.

O relato do padre Biraghi demonstra que as concepções do catolicismo popular eram associadas, pelo clero, à falta de correta instrução religiosa. $\mathrm{O}$ esforço no sentido de normalizar as práticas religiosas dos católicos foi amplo e vigoroso. Mas, encontrou uma resistência igualmente forte. Assim que chegaram a Macapá, os padres do PIME procuraram disciplinar práticas que consideravam desviantes da doutrina oficial da Igreja,como o apego dos leigos a certas imagens de santos. Conforme ressaltamos antes, os padres não viam diferenças de importância entre elas e, portanto, estavam mais preocupados com a quantidade (considerada) exagerada e com aspectos estéticos. D. Aristides

\footnotetext{
Amapà: missione nell'Amazzonia brasiliana, Le missioni cattoliche, n. 3468, mai. 1964, p. 268. Lemos no original:

(...) un giorno, arivato in un villaggio, dopo il solenne ricevimento secondo il programma, andai a visitare subito la cappella, mi indinocchiai e mi misi a pregare. Dopo un pó, incuriosito, fissai l'altare cercando d'indovinare i nomi di quello squadrone di Santi e Sante, ornati con lunghi e coloriti nastri, collocati sui tradizionali tre gradini, quase senza lasciar spazio per celebrare la S. Messa.

Ad un certo punto, tra quello stuolo di Santi e Sante (erano 26...!) vidi qualcosa che proprio santo non era e che non poteva neppure diventarlo mai!...

Chiamai il primo zelatore della cappella e domandai:

- Perchè questo gatto di gesso qui sull'altare e in mezzo ai Santi, quasi in un posto privilegiato?

Mi rispose: - Sa, Padre, il gatto è amico dell'uomo come il Santo; è fedele e familiare, ci sta sempre vicino. E poi, non avevo altra cosa più bella in casa per ornare l'altare...

Che ne pensate voi, amici miei Iontani? Io non me ne meravigliai troppo. Se questa povera gente que vede il Sacerdote una volta l'anno mette innocentemente un gatto sullo stesso gradino del Santo - pensai - so pure bene che nella modernissima e progredita Italia ce n'è dell'altra che alle volte exagera, perchè coscientemente venera più i gatti che i Santi... Almeno questi miei amici li mettono sullo stesso piano!

Debbo dire però, per concludere, che quel giorno stesso mandai il gatto di gesso ad arricchire la pesca di beneficenza che si teneva a favore della cappella.
} 
Piróvano descreveu, na já citada entrevista, as primeiras tentativas dos padres do PIME de remover as estátuas mais deterioradas que eles encontraram na matriz, em 1948: "quando, nos primeiros dias, tentamos colocar de lado ou eliminar alguma estátua, cortar alguma fita mais suja, as pessoas começaram a nos olhar torto!”. E completou: “estavam tão ligados àquele panorama, que arriscávamos ser considerados como protestantes ou hereges" ${ }^{19}$

\section{Pluralismo religioso}

Para muitos fiéis, o que mais fundamentalmente identificava um católico era o culto aos santos. Por causa das restrições que tentavam impor à veneração dos santos, mais de uma vez os padres do PIME foram equiparados aos protestantes. Padre Lino Simonelli destacou que quando manifestara estar irritado com a devoção ao aludido "São Benedito do urupê", uma senhora do Apostolado da Oração lhe dissera: "mas o senhor é um padre católico ou protestante? Porque os protestantes são contra os Santos, mas os católicos não" (Gheddo, 1998, p. 94). No ensaio Progresso e progressismo, publicado em Macapá no ano de 1969, o professor José Benevides asseverou: "uma das coisas mais belas da Igreja Católica e que a distingue das outras religiões é exatamente o culto aos Santos e a veneração à santas imagens". E completou: "padres progressistas e freiras patetas vão falando contra o culto às imagens, tão queridas de nosso povo, sob o falso pretexto de que as imagens provocam a idolatria dos católicos menos letrados, afirmação, porém, aprendida com seus mentores protestantes" (Benevides, 1969, p. 41-42). ${ }^{20}$ Um coro de vozes se levantou contra os ataques do clero à centralidade do culto às imagens na religiosidade dos trabalhadores. Estas vozes replicavam que os padres é que estavam se desviando da verdadeira fé católica, uma vez que eles adotavam ideias inerentes ao protestantismo. Os próprios protestantes não podiam ignorar a força desse culto. Em janeiro de 1960, o jornal A voz católica denunciou que uma pastora mentiu a crianças do bairro do Laguinho, dizendo que, ao contrário do que pensavam, a igreja dela tinha sim santos. E, quando os meninos foram visitar tal igreja, ela lhes apresentara duas imagens. ${ }^{21}$

A acusação de estarem alinhados com postulados protestantes deixava os padres do Pontifício Instituto numa posição muito desconfortável. Isto porque eles faziam severas críticas ao protestantismo, dando ênfase aos antagonismos existentes entre este e o catolicismo. ${ }^{22} \mathrm{~A}$ intolerância e a rispidez recíprocas foram as principais características na relação do clero com os membros das Igrejas protestantes. Isto durou até o Concílio Vaticano II, que estandardizou o

\footnotetext{
${ }^{19}$ Amapà: missione nell'Amazzonia brasiliana, Le missioni cattoliche, n. 3468, mai. 1964, p. 260.

${ }^{20}$ Trata-se de um livro com conteúdo bastante reacionário, com duríssimas críticas à Teologia da Libertação e aos efeitos dela na pastoral e liturgia católicas.

${ }^{21}$ Sistema protestante. A voz católica (Macapá), n. 14, 31 jan. 1960, p. 4.

${ }^{22}$ A Igreja e o Protestantismo. A voz católica (Macapá), n. 2, 08 nov. 1959; O Protestantismo é anti-evangélico. As discrepâncias sectárias. A voz católica (Macapá), n. 12, 17 jan. 1960.
} 
ecumenismo como uma das diretrizes prioritárias da renovação católica. ${ }^{23} \mathrm{Em}$ janeiro de 1960, A voz católica advertia: "quem matricula seu filho em escola protestante, faz pecado mortal, pois o põe no perigo de perder a fé". ${ }^{24}$ Em novembro daquele ano, o mesmo semanário insistia: "é lastimável que muitos católicos mandem seus filhos à escola protestante", o que "constitui pecado mortal para os pais, que incorrem também na excomunhão". ${ }^{25}$ No período aqui estudado, o número de protestantes na Amazônia e no Amapá cresceu rapidamente. Mas, em que pese este crescimento, o clero local estava menos preocupado com o protestantismo do que com o pluralismo religioso praticado por muitos leigos.

\section{Os santos eram aliados importantes na luta cotidiana pela sobrevivência}

Os padres usavam termos como espiritismo e superstição tanto para designar a Pajelança de matriz Tupi, quanto para se referir às religiões de matriz africana (principalmente a Umbanda e o Candomblé). Por isso, D. Piróvano afirmava em 1964: "o protestantismo não constitui o maior obstáculo à fé, pois o espiritismo atinge um percentual maior da população e se mistura facilmente à vida cristã". E mais: "as práticas supersticiosas, fruto da ignorância, do longo isolamento e do escasso contato com sacerdotes, e também da índole sentimental do povo, são erradicadas com dificuldade; é um trabalho que vai requerer gerações" ${ }^{26}$ Nos primeiros anos de trabalho no Amapá, os missionários do PIME perceberam que muitos fiéis frequentavam rituais "espíritas" e que faziam isto despreocupadamente - ou seja, pensando que não estavam cometendo pecado algum. Lino Simonelli relatou que ele e outros padres notaram que todas as senhoras do Apostolado da Oração frequentavam as assembleias de espiritismo. Disse que ficaram sabendo de tal fato algum tempo depois do início da obra missionária e, então, resolveram organizar um "juramento anti-espiritismo". Porém, posteriormente, perceberam que para elas dizer "juro" não tinha muito significado, pois "juravam tranquilamente e depois voltavam

\footnotetext{
${ }^{23}$ Em entrevista concedida à revista Le missioni cattoliche, o bispo prelado de Parintins (AM) D. Arcangelo Cerqua, quando perguntado sobre como era a relação entre católicos e protestantes na Amazônia, declarou: "não [são] muito boas, por causa da propaganda agressiva que distingue especialmente as seitas, Adventistas, Pentecostais, etc. Porém, após o apelo do Concílio Ecumênico e em seguida ao espírito ecumênico que se disseminou por todos os lados, as relações melhoraram, embora não muito" (La Chiesa missionaria nell'Amazzonia brasiliana, Le missioni cattoliche, n. 3453, dez. 1962, p. 484.). No original: "non molto buone per la propaganda aggressiva che contragdistingue specialmente le sette, Avventisti, Pentecostali, ecc. Dopo l'indizione del Concilio Ecumenico ed in seguito allo spirito ecumenico che si è sparso dappertuttto, i rapporti sono però migliorati, ma non troppo".

${ }^{24}$ Crônica das paróquias. A voz católica, n. 13, 24 jan. 1960, p. 3.

${ }^{25}$ Escolas católicas e escolas protestantes. A voz católica, n. 57, 27 nov. 1960, p. 4.

${ }^{26}$ Amapà: missione nell'Amazzonia brasiliana, Le missioni cattoliche, n. 3468, mai. 1964, p. 260. No original: "il Protestantesimi non costituisce attualmente il maggior ostacolo alla Fede, poichè lo spiritismo raggiunge una percentuale più alta di popolazione e si mescola facilmente alla vita cristiana; le pratiche superstiziose, frutto di ignoranza, del lungo isolamento e degli scarsi contatti col sacerdote, ed anche dell'indole sentimentale del popolo, si sradicano com difficoltà: è um lavoro che richiederà generazioni...."
} 
às reuniões espíritas". Diante disto, decidiram fazer algo mais enérgico... Nas palavras do padre Simonelli: "reforçamos o juramento dizendo para repetirem conosco: 'que um raio me incinere, que um anjo me esquarteje com a sua espada se eu voltar às reuniões do espiritismo'. Aquelas pobres mulheres tremiam, mas repetiam a fórmula e obtínhamos alguns efeitos positivos" (Gheddo, 1998, p. 93-94). ${ }^{27}$

Frequentados por "bons católicos", os rituais de pajelança tinham suas raízes no xamanismo dos grupos Tupi que, ao longo de séculos, foram incorporando elementos oriundos das crenças católicas, kardecistas e africanas. A principal finalidade destes rituais era a realização de curas pelo pajé (Arenz, 2003, p. 127-128). A doença no discurso popular era atribuída a um desequilíbrio que envolvia todos os aspetos da vida do enfermo, inclusive o espiritual. ${ }^{28}$ Por isso, a seção de cura reservava um momento para que o enfermo fizesse um relato de sua história pessoal. O pajé era o expert religioso que, por meio de uma experiência extática e de técnicas mágicas, realizava uma mediação entre mundo natural e sobrenatural, visando à solução de males e sofrimentos. A experiência mística do êxtase permitia que ele incorporasse espíritos que os ribeirinhos chamavam de caruanas. Estes entes vinham para operar a cura. Contudo, diferentemente dos santos católicos, os caruanas podiam agir tanto para beneficiar, quanto para "malinar" (prejudicar) as pessoas. Isto ocorreria, por exemplo, através de um "mau-olhado" (feitiço) lançado quando tais espíritos saíam de seu reino (a cidade dos encantados, situada no fundo dos rios) e assumiam a forma de: visagens como curupiras e anhangas; "bichos do fundo" (especialmente botos e cobras grandes); e "bichos visagentos" (inhambu, guariba, veado e outros) (Galvão, 1955, p. 88-111).

Apesar do contrabando de práticas e objetos entre Pajelança e catolicismo ter gerado campos de hibridismo (e até de sincretismo) religioso, foram mantidas as fronteiras entre estas religiões. Podemos dizer que a perseguição que os padres empreenderam contra os pajés chegou mesmo a reforçar tais limites. O antropólogo Raymundo Maués afirma que, antes do início das ações restritivas realizadas por missionários de várias ordens, os rituais de incorporação de caruanas ocorriam em público. Depois disto (e especialmente depois da pedagogia do medo protagonizada pelos agentes da Inquisição), mais e mais tais rituais foram se tornando privados (realizados em casas particulares e para um pequeno grupo de pessoas convidadas) e se cercando de sigilo. O permanente cruzamento dessas fronteiras demonstra o vigor de uma religião estigmatizada e reprimida durante séculos (Maués, 1995, p. 71-72).

\footnotetext{
${ }^{27}$ Le-se no original: "le signore dell'Apostolato della Preghiera erano tutte dentro le assemblee dello spiritismo. L'abbiamo saputo dopo un po' e allora abiamo organizzato un 'giuramento anti-spiritismo', ma ci accorti che per loro dire 'giuro' non aveva molto significato. Lo dicevano tranquillamente e poi ritornavano alle riunioni spiritiche. Allora abbiamo rafforzato il giuramento dicendo di ripetere con noi: 'Che un fulmine mi incenerisca, che un angelo mi squarti con la sua spada se io ritorno alle riunione dello spiritismi'. Quelle povere donne tremavano, ma ripetavano la formula e qualche effetto positivo l'ottenevamo".

${ }^{28} \mathrm{~A}$ antropóloga Paula Monteiro bem destacou que neste discurso o entendimento do "estar doente" pesava pela "noção de uma desordem que extrapola o corpo individual ao abranger as relações sociais e a própria organização do mundo material” (Monteiro, 1985, p. 129).
} 
Muitas pessoas também transitavam entre o catolicismo e as religiões de matriz africana (Candomblé e Umbanda). Comentando esta prática, D. Maritano afirmou que o povo do Amapá era profundamente religioso e que possuía "uma grande tendência ao sincretismo, pois pega[va] tudo o que existe nessa área". E ele completou: "não é incomum encontrar um católico que frequenta ao mesmo tempo a missa, a macumba e o rito da assim chamada Prece Poderosa. As pessoas mais simples pensam mesmo que quanto mais ritos e centros religiosos se frequentam mais se agrada a Deus". ${ }^{29}$ Em um artigo publicado no jornal Amapá,em abril de 1964, Felippe Gilletafirmou: “é próprio do nosso pequeno povo fazer uma amálgama de religiões e crenças de tôda sorte, e socorrer-se desta ou daquela, conforme os transes de sua existência". E prosseguiu: "se se trata de afastar atrasos da vida, apela para a feitiçaria; se se trata de curar uma moléstia tenaz e resistente, procura o espírita; mas não falem à nossa gente em deixar de batizar o filho pelo sacerdote católico, porque não há quem não se zangue". ${ }^{30} \mathrm{O}$ pluralismo religioso dos populares brotava da concepção fundamental de que todas as forças espirituais que pudessem ser carreadas para o campo das lutas contra os males da vida eram sempre bem vindas. Esta junção de várias crenças na luta cotidiana (contra a insegurança, a dor e a morte) chocava-se com o exclusivismo intolerante do clero. Este primava pela exclusão de tudo aquilo que estivesse distante da chamada verdadeira fé.

\section{A dialética da romanização}

O esforço dos sacerdotes para afastar os fiéis das práticas consideradas desviantes estava ligado ao processo de romanização, iniciado no final do século XIX. Neste momento - em que a Igreja adquire maior autonomia em relação ao Estado - o alto clero brasileiro definiu uma série de estratégias para expurgar do laicato as referidas práticas. A principal delas foi a ampliação do número de dioceses e paróquias, para nelas garantir a presença de clérigos. A presença constante de padres dentro ou próximo das comunidades propiciaria um controle maior da vida religiosa dos católicos (Maués, 1995, p. 59-85). $\mathrm{O}$ argumento de que existia uma urgente necessidade desta presença em áreas onde havia uma evangelização incompleta foi utilizado pelo bispo prelado de Santarém para persuadir os missionários do Pontifício Instituto a irem trabalhar no Amapá. E neste Território Federal, seguindo as diretrizes romanizadoras, os padres do PIME travaram um acirrado combate contra as festas realizadas em homenagem aos santos. D. Piróvano assim descreveu tais festejos:

\footnotetext{
29Un vescovo in Amazzonia, Mondo e missione, n. 20, out. 1979, p. 530. Lemos na revista Mondo e missione: “il popolo dell'Amapá è profondamente religioso, noi diciamo 'troppo religioso', nel senso che ha una grande inclinazione al sincretismo: prende tutto quel che c'è in questo campo; non è difficile trovare un cattolico che frequenta contemporaneamente la Messa, la macumba e il rito della considdetta Prece Poderosa. La gente più semplice pensa addirittura che più riti e centri religiosi si frequentano e più si piace a Dio".

${ }^{30}$ Gillet afirmou que de 1920 (quando Barreto escrevera tal coisa) até 1964 esta prática não mudara, ou, se mudara, fora para se acentuar (Gillet, 1964, p. 3).
} 
(...) as pessoas se vestem o melhor que podem e levam consigo tudo o que têm... À tarde, em geral, há a procissão religiosa em honra a esse ou àquele Santo e, se o sacerdote está presente, também a benção eucarística, as confissões e as orações litúrgicas. À noite, por sua vez, as pessoas dançam, com o acompanhamento de alguma pequena orquestra improvisada ou, se o vilarejo é importante e pode se permitir a esse luxo, trazida de longe; dança-se e bebe-se a cachaça, álcool muito forte extraído da cana de açúcar, são feitos vários jogos e desafios, há conversas e discussões... Tudo isso dura às vezes até a manhã e não raramente terminam em brigas, esfaqueamentos e pancadarias, e pecados que podemos facilmente imaginar... Nós procuramos estar presentes o mais possível nestas festas populares, para evitar os excessos e para lhes dar um tom religioso. Mas serão necessários muito tempo e muita paciência: os maus hábitos não são perdidos em um dia. ${ }^{31}$

Os padres usavam termos como espiritismo e
superstição tanto para designar a Pajelança de matriz
Tupi, quanto para se referir às religiões de matriz
africana

Por tentar restringir aquilo que havia de mais prazeroso, o padre era alguém indesejado nas festas populares. Nos relatos clericais, sempre se ressaltava que dos festejos derivava um condenável quadro de degradação moral: bebedeiras, brigas, jogos, seduções e estupros. ${ }^{32}$ Um fato viria dar maior gravidade a esta percepção. Em 1950, sob a direção do padre Antonio Cocco, iniciaram os trabalhos de construção da Igreja de Nossa Senhora da Conceição, no bairro macapaense chamado de Trem. Como o principal problema na realização desta obra era a falta de dinheiro, pessoas entusiasmadas sugeriram que padre Cocco organizasse uma quermesse durante o ciclo de comemorações do aniversário

\footnotetext{
${ }^{31}$ Amapà: missione nell'Amazzonia brasiliana, Le missioni cattoliche, n. 3468, mai. 1964, p. 263. Lemos na Le missioni cattoliche: "la gente si veste del suo meglio e porta con sè tutto il suo avere... Al pomeriggio in genere c'è la processione religiosa in onore di questo o quel Santo e, se è presente il sacerdote, anche la benedizione eucaristica, le confissioni e preghiere liturgiche. Alla sera invece la gente balla, con l'accompagnamento di qualque orchestrina improvvisata o, se il villaggio è importante e può permetterselo, fatta venire da lontano: si balla e si beve la cachaça, alcool molto forte estratto dalla canna da zucchero, si chiacchiera e si discute... Tutto questo dura a volte fino al mattino e non di raro finisce in risse, coltellate e bastonate, e peccati facilmente immaginabili... Noi cerchiamo di essere presenti il più possibile a queste feste popolari, anche per dar loro un tono religioso. Ma ci vorrà del tempo e molta pazienza: le cative abitudini non si perdono in un giorno". ${ }^{32}$ Relatando sua experiência missionária no Amapá, na revista eclesiástica // Vincolo de setembro de 1953, o padre Carlo Bassanini afirmara: "anos atrás, as festas de alguns santos: São Sebastião, São Benedito Negro, Santo Antonio, São Raimundo, N. S. de Nazaré, a Imaculada, etc. eram celebradas mais pelos pagãos que pelos cristãos. Todas as noites, durante a novena, o povo, quase todos já com roupa para o baile e instrumentos musicais, reunia-se na capela: uma espécie de "rezador" rezava o terço; alguém respondia e outros davam risadas. Depois, após ter gritado uma espécie de ladainha de Nossa Senhora e alguma oração, os "músicos" começavam a tocar, dando início ao baile que ia até às três, quatro da madrugada, acabando com certa frequência em brigas e pauladas. Agora conseguimos diminuir os bailes e realizar a festa do santo com um pouco de devoção" (Bassanini apud Negri, s/d., p. 45).
} 
da criação do Território do Amapá. Financeiramente, a festa foi bem sucedida: foram apurados 18 mil cruzeiros - utilizados na compra de telhas. Quando retornou de Belém, aonde fora comprar as referidas telhas, aquele padre ficou chocado ao ser informado pela Polícia de que "durante a confusão de sua festa ocorreram onze estupros!", pois, “aproveitando a escuridão, vários jovens pegavam uma moça, arrastavam-na para trás do muro da igreja (que já tinha dois metros de altura) e a estupravam". O clérigo reuniu os fiéis e disse-lhes que não mais seriam realizadas festas para a construção da igreja (Gheddo, 1998, p. 77).

Neste mesmo ano, D. Aristides Piróvano publicou uma carta pastoral contra os bailes. Dizia-se que ela tinha sido escrita pelo padre Cerqua, que então era vigário geral, e que Piróvano a tinha apenas assinado. Segundo padre Bubani, a carta tinha sido solicitada pelos sacerdotes que trabalhavam na Prelazia. Esta pastoral condenava os bailes realizados após as festas religiosas e ameaçava os fiéis com raios e excomunhões. Segundo tal documento, as festas dançantes eram fonte de desordem moral e nelas aconteciam sempre brigas, bebedeiras e esfaqueamentos. Os padres do PIME passaram então a contar com a ajuda do governo territorial para dar plena execução àquilo que o bispo prelado de Macapá determinava. Em correspondência de 07 de abril de 1951, D. Piróvano escreveu ao Superior do Pontifício Instituto que, reconduzido ao cargo de governador, Janary Nunes pela primeira vez não organizara festas dançantes oficiais e, além disto, solicitara expressamente uma missa, a mais solene possível. E o bispo acrescentou: "até no interior os chefes de polícia deram ordens para apoiar os padres, para que fossem obedecidos e para que não se permitissem danças durante as festas religiosas" (Gheddo, 1998, p. 76).

Mas, para defender suas tradições, os festeiros várias vezes não hesitaram em desafiar os padres. Segundo Piero Gheddo, após a publicação da carta pastoral que proibia os bailes, os missionários do PIME "experimentaram a dureza das reações populares (alguns correram o risco de serem jogados na água!)". Numa visita que fizera ao município de Amapá, Janary foi homenageado com um baile. Padre Bubani, reprovando tal iniciativa, suspendeu a festa religiosa, retirou as bandeiras e as insígnias da igreja e se recusou a fazer a procissão e as demais funções clericais. Vendo isto, o governador lhe disse: "padre, eu entendo seus motivos, mas o senhor deve compreender os nossos. Esta pobre gente não tem nada, diverte-se apenas com um pouco de saltos e danças..." (Gheddo, 1998, p. 75). Aos poucos, os missionários foram percebendo que não poderiam seguir sendo tão rigorosos. Habilidosamente abriram mão de algumas exigências e transigiram diante de algumas práticas. Portanto, não ocorreu em Macapá uma inexorável romanização, ou um rolo compressor que, esmagando o catolicismo popular, homogeneizasse a vida religiosa. Ocorreu, sim, um processo dialético, onde tanto o clero quanto os populares negociaram, aquiesceram e incorporaram novas concepções e práticas.

Na entrevista que concedeu ao padre Piero Gheddo, em 1964, D. Piróvano disse que os missionários do PIME encontraram notáveis dificuldades para impor os deveres morais cristãos, mesmo os mais simples como: a missa 
dominical, a instrução religiosa, o matrimônio indissolúvel, a confissão e a comunhão pelo menos uma vez por ano. As pessoas, no início, diziam que eles eram exagerados. Diante disto, os clérigos tiveram que agir com cautela, para não criar inimizades e, assim, prejudicar o trabalho religioso. Segundo aquele bispo, os sacerdotes buscaram nos primeiros anos conquistar a simpatia e a amizade dos leigos com obras sociais e com a escola, mas sem pretender que eles se tornassem cristãos exemplares em pouco tempo. Explicou D. Piróvano: "tínhamos que fechar um olho e às vezes ambos, convencidos de que o tempo teria resolvido várias coisas". ${ }^{33}$ Notando tal condescendência, o poeta Álvaro da Cunha escreveu: "Dom Aristides sincrético assumia/ senão a incoerência [e] a inocência, o idólatra, não a idolatria/ depois sorria [e] novamente ressorria/ e ia rezar por nós no altar-mor da Prelazia" (Cunha, 1986, p. 18).

\section{Esta junção de várias crenças na luta cotidiana (contra a insegurança, a dor e a morte) chocava-se como exclusivismo intolerante do clero}

As obras sociais (escolas, orfanato, hospital, etc.) criavam um vínculo de gratidão muito forte. Para cativar os paroquianos, os padres realizaram uma série de ações voltadas para as crianças e os jovens. Mesclavam a catequese com atividades esportivas e lúdicas. A este respeito, relatou o primeiro bispo de Macapá: "nosso primeiro trabalho foi nos aproximarmos e conquistar a amizade das crianças e dos jovens, e tivemos missionários, como Pe. Lino Simonelli, que fizeram um trabalho maravilhoso nesse sentido". Em frente a quase todas as igrejas havia praças com campos de futebol, quadras para voleibol e outros jogos e brincadeiras. Os padres também promoveram para os pequenos fiéis: operetas, projeções de filmes e passeios. Por exemplo, Padre Vittorio Galliani começou com um campo para jogar bola e, depois, passou a projetar filmes... Padre Simonelli relatou: "lembro-me quando passamos o primeiro filme (de oito milímetros) que era sobre a vida de Jesus, homens e mulheres choravam comovidos, até mesmo o governador Janary chorava" (Gheddo, 1998, p. 49). ${ }^{34}$

Se por um lado os padres reprovavam duramente as festas promovidas por irmandades leigas, por outro organizavam grandes festejos religiosos. $\mathrm{O}$ Círio de Nazaré e a comemoração do dia de São José - padroeiro de Macapá - eram festas controladas pelo clero e atraíam muitas pessoas para a cidade. A crescente devoção a Nossa Senhora do Perpétuo Socorro também recebeu

${ }^{33}$ Amapà: missione nell’Amazzonia brasiliana, Le missioni cattoliche, n. 3468, mai. 1964, p. 259.

${ }^{34}$ No original lemos: "mi ricordo quando abbiamo fatto il primo film (a otto milimetri), che era sulla vita di Gesú, uomini e donne piangevano di commozione, persino il governatore Janarí piangeva". 
grande incentivo dos sacerdotes e da imprensa católica. ${ }^{35}$ Em julho de 1962, o articulista do jornal A voz católica comentou que todas as terças-feiras centenas de pessoas - "gente de tôdas as cores, de tôdas as idades, de tôdas as camadas [sociais]" - acorriam ao santuário de Nossa Senhora do Perpétuo Socorro para agradecer ou pedir graças.

Os padres viam a forte devoção mariana como uma estratégia para promover a sacramentalização. Segundo eles: "a verdadeira devoção a N. S. do Perpétuo Socorro é aquela que nos chega aos santos sacramentos". ${ }^{36}$ Entretanto, para desapontamento do clero, muitos devotos assistiam às novenas, mas não às missas. Muitas pessoas só assistiam às missas nos dias das grandes festas religiosas. No citado semanário católico lemos: "há muita gente que se diz católica mas só vai à Igreja no dia do Círio". ${ }^{37} \mathrm{Na}$ verdade, não havia um consenso acerca do que significava ser católico. Coexistiam formas diferentes de vivência da fé. O jornal A voz católica de 07 de abril de 1963 comentava a existência de três tipos de católico. $\mathrm{O}$ "católico de arraial" aguardava ansiosamente a realização das grandes festas religiosas a fim de usufruir exclusivamente da parte profana delas. Já o "católico de papelão" era aquele afeito a grandes solenidades, ocasião em que procurava ocupar lugar de destaque, chamando a atenção para si através da doação de um sino, de uma imagem ou de algo do gênero. Por fim, o "católico de fita" era o cristão pertencente a qualquer congregação religiosa (Filhas de Maria, Conferência Vicentina, Apostolado da Oração, etc.), "mas com a ideia fixa [de]que só isso basta[va] para ser católico". ${ }^{38}$ Ainda que de forma estereotipada, esta classificação permite perceber a diversidade de experiências que a Igreja Católica abrigava. Não obstante o esforço homogeneizador dos agentes da romanização, esta diversidade se manteve e é possível que tenha até se ampliado, com o aparecimento de novas combinações.

\section{Palavras finais}

O ano de 1964 marcou o início de profundas mudanças na Igreja. Estava encerrando o Concílio Vaticano II (1962-1965), que determinou uma maior aproximação e entendimento entre clérigos e leigos. Conforme o padre Teodoro Negri, “começa-se também a falar de 'inculturação', isto é, a evangelização devia ser feita de acordo com a cultura e as tradições do povo da terra para onde o missionário é enviado" (Negri, s/d, p. 43). Também em 1964, D. Aristides Piróvano (que desde 1948 vinha presidindo a missão dos padres italianos) deixou a

\footnotetext{
${ }^{35} \mathrm{~A}$ capela de Nossa Senhora do Perpétuo Socorro foi inaugurada no Igarapé das Mulheres em 1958; mas, "tendo-se demonstrado pequena para o grande concurso de povo, foi novamente ampliada [com o acréscimo de duas naves laterais] pelo Pe. Angelo Biraghi e reinaugurada por D. Aristides Piróvano a O2.10.60"(Bubani, 1983, p. 66)

${ }^{36}$ A devoção a N. S. do Perpétuo Socorro na cidade de Macapá. A voz católica (Macapá), n. 142, 15 jul. 1962, p. 2.No artigo "O sentido de uma devoção", lemos: "não esqueçamos, porém, que Maria deve nos levar ao Cristo. E o Cristo está na Eucaristia. Portanto a súplica mais poderosa, a devoção mais legítima é aquela que se acampanha [sic.] à Santa Comunhão, a união de nossas almas com a divindade" (O sentido de uma devoção. A voz católica (Macapá), n. 143, 22 jul. 1962,p. 2).

37Um dever preterido.A voz católica (Macapá), n. 142, 15 jul. 1962, p. 2

${ }^{38}$ Pingo no 'l' [seção]. A voz católica (Macapá), n. 180, 7 abr. 1963, p. 3
} 
direção da Prelazia de Macapá para se tornar Superior Geral do PIME, em Milão. Seu substituto no episcopado amapaense foi D. Giuseppe Maritano, que empreendeu um movimento de renovação pastoral fundamentado na ação laica e organizado em torno das Comunidades Eclesiais de Base (CEB's) - pequenos grupos de famílias vizinhas. ${ }^{39}$ Iniciava-se, assim, um processo de mudança na forma dos padres se relacionarem com os populares. Os "métodos italianos" - baseados na sacramentalização e na normalização das práticas percebidas como desviantes (catolicismo popular) — passaram a ser alvo de frequentes críticas. ${ }^{40}$

As mais rigorosas investidas clericais para ajustar as práticas religiosas populares à doutrina oficial da Igreja foram pouco frutíferas. Em geral, foi no bojo destas empreitadas reguladoras que foi gerada a maior parte dos registros que utilizamos a fim de conhecer os aspectos fundamentais da religiosidade dos trabalhadores. Todo o período aqui estudado foi marcado por fortes tensões entre a ortodoxia clerical e as iniciativas devocionais populares. Não obstante os esforços dos padres para homogeneizar as práticas cristãs, segundo uma interpretação ortodoxa dos cânones católicos, um caleidoscópio de experiências religiosas continuou marcando a vida macapaense.

Este artigo originou-se de parte da tese de doutorado A cidade dos trabalhadores: insegurança estrutural e táticas de sobrevivência em Macapá (19441964), elaborada sob a orientação da Dra. Maria Odila Leite da Silva Dias e defendida no Programa de Pós-Graduação em História Social da Universidade de São Paulo (USP), em 2013.

\section{Referências bibliográficas}

ARENZ, Karl Heinz. São e salvo: a pajelança da população ribeirinha do Baixo Amazonas como desafio para a evangelização. Quito (Equador): ABYA-YALA, 2003.

BENEVIDES, José. Progresso e progressismo. Macapá: Artes Gráficas do Ginásio de Macapá, 1969. BUBANI, Angelo. Diocese de Macapá. Macapá: Diocese de Macapá, 1983.

CAVALIERE, Ivan Fornazier. Padre Júlio Maria Lombaerde na memória do povo de Macapá. Juiz de Fora: Gráfica Floresta, 1981.

CUNHA, Álvaro da. Amapacanto, Macapá: Imprensa Oficial do Amapá, 1986.

GALVÃO, Eduardo. Santos e visagens: um estudo da vida religiosa de Itá; Amazonas. São Paulo: Companhia Editora Nacional, 1955.

GHEDDO, Piero. Missione Amazzonia: 50 anni del Pime nel Nord Brasile (1948-1998). Bologna: EMI, 1998.

. PIME: 150 anni di missione (1850-2000). Bolonha: EMI, 2000.

GILLET, Felippe. Recordando um conto, Amapá, n. 235, 26 abr. 1964.

LOMBAERDE, Júlio Maria. Diário do Pe. Júlio Maria. Belo Horizonte: O lutador, 1991.

\footnotetext{
${ }^{39}$ Segundo o padre e pesquisador da história do PIME Piero Gheddo: "Mons. Maritano, parroco prima ad Assis nel Brasile Del sud e poi a Manaus, imposta súbito um programma di rinnovamento pastorale, centrato sull'apostolato dei laici e sulle 'comunità ecclesiali di basi', Che in quel tempo si diffondevano in Brasile e in América Latina: nel 1979 nell'Amapá sono giá 400 com 150 catechisti e centinaia di altri ministri laici" (Gheddo, 2000, p. 880).

${ }^{40}$ Os "animadores de CEB" e "coordenadores de setor" recebiam formação catequética no Centro de Catequese Diocesano. Este centro foi criado em 1963 e foi incialmente dirigido pelo padre Paolo De Coppi, que adotou o slogan: "por uma catequese aculturada na Amazônia" (Gheddo, 2000, p. 877).
} 
MAUÉS, Raymundo Heraldo. Padres, pajés, santos e festas: catolicismo popular e controle eclesiástico. Um estudo antropológico numa área no interior da Amazônia. Belém: Cejup, 1995.

.Um aspecto da diversidade cultural do caboclo amazônico: a religião. In: VIEIRA,Ima et al. (orgs.). Diversidade biológica e cultural da Amazônia. Belém: Museu Goeldi, 2001.

MONTEIRO, Paula. Da doença à desordem. A magia na umbanda. Rio de Janeiro: Graal, 1985. MOTINHA, Katy Eliana Ferreira. A Festa do Divino Espírito Santo: espelho de cultura e sociabilidade na Vila Nova de Mazagão, Tese (Doutorado em História), Universidade de São Paulo (USP). São Paulo, 2003.

NEGRI, Teodoro. Dom Aristides: uma aventura humana e missionária. São Paulo: Mundo e Missão, s/d.

NUNES, Raimundo Peres. São José e os cabanos. A voz católica (Macapá), n. 200, 25 ago. 1963a. São José e os cabanos. A voz católica (Macapá), n. 201, 1 set. 1963b.

OLIVEIRA, Maria do Socorro dos Santos. Religiosidade popular em comunidades estuarinas amazônicas: um estudo preliminar do Marabaixo no Amapá, Scripta Nova - Revista Electrónica de Geografia e Ciencias Sociales da Universidad de Barcelona, n. 45, 1999.

PEREIRA, Nunes. O sahiré e o marabaixo: tradições da Amazônia. Rio de Janeiro: Ouvidor S. A., 1951.

REIS, João José. Religião, rebelião e identidade afro-baiana. Entrevista de Martha Abreu e Ronaldo Vainfas com João José Reis, Tempo, v. 6, n. 11, p. 255-260, 2001.

SOUZA, Marina de Mello. Santo Antônio de nó-de-pinho e o catolicismo afro-brasileiro, Tempo, n. 11, p. 171-188, 2000 